\title{
Healthcare professionals' intentions to use clinical guidelines: a survey using the theory of planned behaviour
}

\author{
Tiina Kortteisto*1, Minna Kaila1,2, Jorma Komulainen3,4, Taina Mäntyranta5 and Pekka Rissanen
}

\begin{abstract}
Background: Finnish clinical guidelines are evolving toward integration of knowledge modules into the electronic health record in the Evidence-Based Medicine electronic Decision Support project. It therefore became important to study which factors affect professionals' intention to use clinical guidelines generally in their decision-making on patient care. A theory-based approach is a possible solution to explore determinants of professionals' behaviour. The study's aim was to produce baseline information for developers and implementers by using the theory of planned behaviour.

Methods: A cross-sectional internet-based survey was carried out in Finnish healthcare organisations within three hospital districts. The target population $(n=2,252)$ included physicians, nurses, and other professionals, of whom 806 participated. Indicators of the intention to use clinical guidelines were observed by using a theory-based questionnaire. The main data analysis was done by means of multiple linear regressions.

Results: The results indicated that all theory-based variables--the attitude toward the behaviour, the subjective norm, and the perceived behaviour control--were important factors associated with the professionals' intention to use clinical practice guidelines for their area of specialisation in the decisions they would make on the care of patients in the next three months. In addition, both the nurse and the physician factors had positive $(p<0.01)$ effects on this intention in comparison to other professionals. In the similar models for all professions, the strongest factor for the physicians was the perceived behaviour control, while the key factor for the nurses and the other professionals was the subjective norm. This means that context- and guideline-based factors either facilitate or hinder the intention to use clinical guidelines among physicians and, correspondingly, normative beliefs related to social pressures do so for nurses and other healthcare professionals.

Conclusions: The results confirm suggestions that the theory of planned behaviour is a suitable theoretical basis for implementing clinical guidelines in healthcare practices. Our new finding was that, in general, profession had an effect on intention to use clinical guidelines in patient care. Therefore, the study reaffirms the general contention that different strategies need to be in place when clinical guidelines are targeted at different professional groups.
\end{abstract}

\section{Background}

Clinical guidelines are systematically developed to assist healthcare professionals and patients in making treatment decisions [1]. In Finland, there are long traditions of developing national electronic guideline databases [2]. These are used via a national health portal http:// www.terveysportti.fi throughout the healthcare system

* Correspondence: tiina.kortteisto@uta.fi

1 Tampere School of Public Health, University of Tampere, Medisiinarinkatu 3, Tampere, Finland

Full list of author information is available at the end of the article (in all primary care centres and secondary care hospitals) [3]. Clinical guidelines seem well disseminated to healthcare organisations, but there is still scant evidence on adoption in clinical practice [4-7].

There are several obstacles to guideline adherence, some of which are related to the professionals, such as lack of awareness, agreement, self-efficacy, and inertia of previous practice. There are also guideline-, patient-, and environmental-related barriers that are influenced further by context [8]. For successful implementation of 
guidelines, there is a need to better understand the complexity of changing clinical practice and especially the implementation problems that relate to professional attitudes and experiences associated with use of guidelines in the healthcare context [9-12].

A theory-based approach is a possible solution for exploring determinants of professionals' behaviour $[13,14]$. The theory of planned behaviour (TPB) is a conceptual framework for understanding human social behaviour $[15,16]$. The TPB states that one central determinant of behaviour is an intention to perform it. The strength of intention consists in three kinds of latent components (see Figure 1). The first component, the attitude toward the behaviour, is composed of human beliefs about consequences of the behaviour. The second component, the subjective norm, is composed of human normative beliefs and social pressure toward the behaviour. The third component, the perceived behaviour control, is composed of human beliefs concerning capability and the controllability of performing the behaviour. The latter can also be directly associated with the behaviour [17].

Applying the TPB to identify which theoretical constructs predict use of guidelines in clinical practice, as has been done in studies among healthcare professionals $[18,19]$, is advisable since intention seems to be a valid proxy measure for behaviour [20]. These studies have targeted either a specific profession, such as gynaecologists [21], or one specific guideline in a specific healthcare setting--for example, hand hygiene among neonatal healthcare workers [22]. One American study [23] examined physicians' compliance with one of four specific sets of clinical guidelines on five practice sites--for example, an asthma guideline among two family practice residency groups. The results show that the perceived behavioural control was the strongest predictor of physicians' behavioural intention.

However, there are still some concerns about the correspondence between an intention and a future behaviour, particularly in healthcare professionals' practice [24], even though intentions explaining $28 \%$ of the variance of behaviour should be considered 'good' [25]. In addition, both nurses' and physicians' self-reported adherence to guidelines have been assessed as greater than their actual use of guidelines [23,26]. Moreover, in a systematic review [19], it was shown that a number of methodological and theoretical moderators may influence the efficacy of prediction of intention.

This study focuses on the general level of clinical guidelines' use in healthcare practice wherein each profession has its own duty concerning, and also relationship to, guidelines. Only a few previous studies applying qualitative methods [27-29] have explored this topic before, none of them in a Finnish context. Here, the TPB-based survey is applied for the first time among several types of professionals (physicians, registered nurses, public health nurses, midwives, ward nurses, physiotherapists, occupational therapists, and others) in both primary and secondary care. In addition, Finnish clinical guidelines are currently evolving from access via the internet environment to integration of knowledge modules into the electronic health record in the Evidence-Based Medicine electronic Decision Support (EBMeDS) project [30-32]. To produce baseline information, it was considered important to study which factors affect professionals' intention to use clinical practice guidelines in making their decisions concerning care of patients. The study

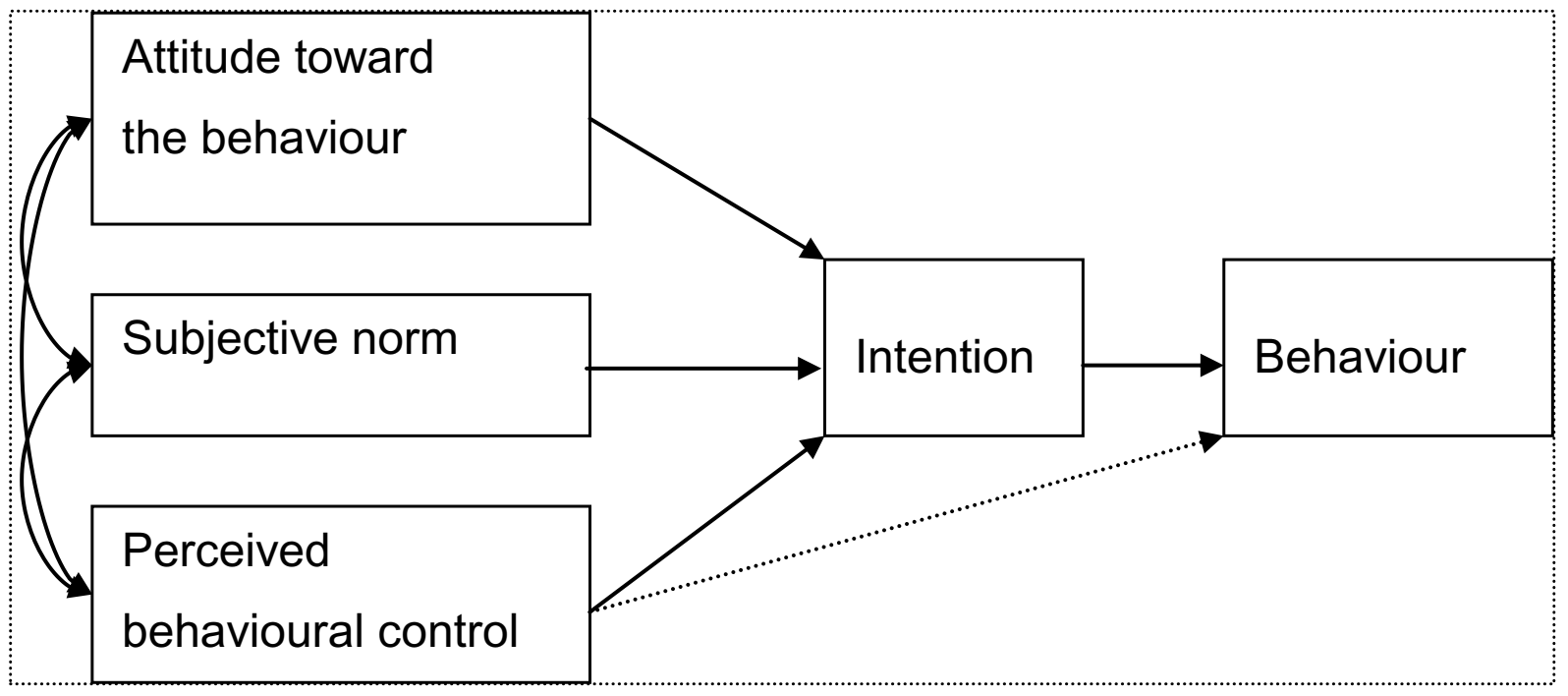

Figure 1 A framework of the theory of planned behaviour [17]; see also [63]. 
questions were as follows: Do healthcare professionals have positive or negative intention to use clinical guidelines for their area of specialisation in their decision-making for patient care? How do healthcare professions differ in their intentions? What factors are associated with healthcare professionals' intention to use clinical guidelines in patient care?

\section{Methods}

\section{Procedures and participants}

A cross-sectional internet-based survey was carried out from October 2006 to May 2007 in publicly funded healthcare organisations $(n=26)$ within three hospital districts, which were to become the pilot sites of EBMeDS. The target population included all physicians, registered nurses, and other healthcare professionals with at least nursing-level education in the Kymenlaakso (KL) and Central-Finland (CF) hospital districts ( $\mathrm{n}=1,400)$; units of dental care, radiology, and laboratory workers were excluded. In the hospital district of Northern-Savo (NS), professionals involved in the care of diabetes were included ( $n=913)$. Different professions were included because the EBMeDS system was to be piloted among all of these groups. The target groups were approached through a contact person nominated from the participating organisations, the chief medical officers of which approved the study.

The final target study population consisted of 2,252 professionals (61 professionals were excluded because of, for example, an invalid e-mail address). After two reminders, 806 healthcare professionals responded: 135 physicians (out of 463), 552 nurses (out of 1,477), and 112 other professionals (out of 312).

\section{Questionnaire}

A questionnaire was designed by the EBMeDS study group complemented by two advisers with psychology degrees. The aim was to develop a multifaceted and practical questionnaire consisting of relevant questions. Therefore, the first two questionnaires were constructed to be of differing length. These were piloted among a convenience sample of healthcare professionals $(n=56)$ randomised into two groups [33]. Pilot group one were given the longer questionnaire one, and pilot group two received the shorter version two, in an internet-based survey. The response rate increased from $22 \%$ to $44 \%$ in group one, and from $36 \%$ to $50 \%$ in group two after one reminder. The respondents gave valuable feedback, such as that questionnaire one was too long, questions were targeted more to physicians than nurses, there were too many issues addressed within one question and by the questionnaire overall, and formulation of a very informative covering letter would encourage responses.
Next, JK and TK carefully considered each question in relation to the objectives of the EBMeDS project. The EBMeDS study group reflected on the feedback and then abbreviated the questionnaire to 27 questions in the following areas: information technology questions, which included nine questions about the usefulness of and satisfaction with the electronic patient record and information databases; guideline questions, which involved the Attitudes towards Guidelines Scale [34] and included also the TPB-based items; job content questions, which applied a concise form of the Job Content Questionnaire [35]; and questions on the respondent's individual and organisational background. Four investigators tested the technical validity of the internet questionnaire. Here, we included the TPB-based items and background questions (see Additional File 1). A covering letter described the objectives of the study, with a link to the web pages of the EBMeDS project, approval of the study, and investigator information [33].

\section{Indicators}

The items in the guideline-based set of questions were designed according to the principles of the brief form of the TPB questionnaire manual [36]. In keeping with the principle of compatibility $[17,37,38]$, the four indicators referred to clinical practice guideline use in general, not one specific guideline. The target behaviour is considered to involve a professional's knowing use of patient-specific guidelines in clinical decision-making, which was not directly observed. The dependent variable was an intention, which was measured with one item: 'I intend to use clinical practice guidelines for my area of specialisation in the decisions I make on the care of patients in the next three months.' The first latent component, the attitude toward the behaviour, was assessed by way of three behaviour beliefs associated with the use of clinical practice guidelines. The second latent component, the subjective norm, was assessed in terms of three normative beliefs about social pressures to use clinical practice guidelines. The third latent component, the perceived behaviour control, was assessed with six control beliefs about context and guideline factors that might facilitate or hinder use of clinical practice guidelines. These behavioural, normative, and control belief items were developed by means of a manual [36], earlier evidence [39,40], and guideline-based Finnish national document [41] such that each of them should be relevant and important for healthcare professionals in the Finnish healthcare context. Each item for the variables was assessed directly by the respondent, rated on a seven-point scale: 1 = absolutely negative, 2 = negative, $3=$ probably negative, $4=$ neither negative nor positive, $5=$ probably positive, $6=$ positive, 7 = absolutely positive. 


\section{Analyses}

Statistical analyses were performed with SPSS for Windows, version 15.0. The characteristics of the sample and the dependent variable frequency were analysed with descriptive statistics. Factor analysis with principal component analysis, using the varimax rotation method, was carried out for 12 TPB items in order to verify the discriminant validity of the three predicted variables computed in the analysis [42]. These items were combined according to the theory into three latent components. The internal consistency of the scales, measured via Cronbach's alpha coefficient, was above 0.8 for each of these variables, which can be considered a satisfactory value [43]. Profession group differences for the intention variable were analysed via variance analysis with Welch's and Gamess-Howell's tests, which have been recommended for use in cases of unequal sample sizes and unequal variances [44]. The main data analyses were conducted with multiple linear (ordinary least square) regressions [45]. The models were formed to use the theory-based variables, dummy variables related to respondents (age and gender) and profession in the overall model, and organisation characteristics (healthcare level and hospital district). In the analyses, the variables were directly entered in the model to investigate the effect of each on the professionals' intention to use clinical practice guidelines. The theory-based TPB variables were handled as continuous in the models despite being composed of only seven discrete values. Subjects with missing values were excluded from all analyses. This caused a reduction in the number of respondents, which is reported upon further in the discussion section.

\section{Results}

The e-mail invitation to participate the internet-based survey was followed by two reminders. The overall response rate was $36 \%$; broken down by profession, it was $29 \%$ among physicians, 37\% for nurses, and 36\% for other professions. The majority of the respondents (89\%) were female (see Table 1), and the mean age was 45 years (range: 24 to 67 years). The distribution by profession was $17 \%$ physicians, 69\% nurses (registered nurses, public health nurses, and midwives), and $14 \%$ other professionals in the healthcare field (physiotherapists, ward nurses, occupational therapists, rehabilitation advisers, et al.).

The intention to use clinical practice guidelines in decision making for patient care was more often positive than negative. Overall, $18 \%$ of the respondents indicated absolutely positive and $30 \%$ positive intention, while only $1 \%$ indicated absolutely negative and $4 \%$ negative views. The mean score of the intention variable was 5.5 points for the physicians, 5.3 for the nurses, and 5.0 for the other professionals (see Table 2). The Welch's variance-weighted
ANOVA (asymptotically F 3.83, $\mathrm{p}=0.02$ ) indicated that at least one difference existed between the groups. Further, the Games-Howell's test indicated positive differences between physicians and nurses (mean difference $0.30, \mathrm{p}=0.04)$, and between physicians and other professionals (mean difference 0.42, $\mathrm{p}=0.04$ ).

The factors associated with the professionals' intention to use clinical practice guidelines were analysed via multiple linear regression models. The overall regression model was statistically acceptable $(\mathrm{F}=37.41, \mathrm{p}<0.001)$ and explained $36 \%$ (adjusted $\mathrm{R}$ square) of the variation in the intention to use clinical guidelines. Moreover, the TPB variables, as well as nurse and physician variables, had a positive effect on the intention to use clinical practice guidelines (see Table 3). When similar models were run in both primary and secondary care settings, the positive profession effect on the intention remained among secondary care workers $(\mathrm{B}=0.55, \mathrm{p}=0.01$ among nurses and $\mathrm{B}=0.98, \mathrm{p}<0.001$ among physicians) but did not remain statistically significant among primary care workers. After these results, similar regression models were run in each profession group.

The physicians model explained $48 \%$ variation in the intention to use clinical guidelines (see Table 3). All TPB variables were positively correlated with the intention variable. The strongest of these was perceived behaviour control, showing a positive association with the intention variable. This indicates that the physicians, who had a more positive view of contexts and guideline factors, also intended to use clinical practice guidelines more often. Among the variables of individual and organisation characteristics, only the variable for primary care had a negative effect on the intention variable, thus showing less intention among primary care physicians to use clinical practice guidelines than among secondary care physicians.

The nurses model explained $34 \%$ of the variation in the intention to use clinical guidelines (see Table 3). Of all variables in the model, only the TPB variables were positively correlated with the intention variable. The subjective norm was the strongest factor, indicating that those nurses who perceived social pressure to use clinical practice guidelines also had more positive intention to use them than did nurses who did not perceive social pressure.

The model for other professionals explained $32 \%$ of the variation in the intention to use clinical guidelines (see Table 3). Of all variables, only the subjective norm and the perceived behaviour control were positively correlated with the intention variable. The subjective norm was the strongest factor, indicating that the professionals' perception of social pressure toward the use of clinical guidelines produced positive intention to use them. 
Table 1: Characteristics of the respondents, compared to the target population

\begin{tabular}{|c|c|c|c|c|}
\hline & \multicolumn{2}{|c|}{ Respondents } & \multicolumn{2}{|c|}{ Target } \\
\hline & $\mathbf{n}$ & $\%$ & $\mathbf{n}$ & $\%$ \\
\hline \multicolumn{5}{|c|}{ Gender $(n=792)$} \\
\hline Female & 703 & 89 & 1,948 & 87 \\
\hline Male & 89 & 11 & 304 & 13 \\
\hline Age $(n=788)$ & & & \multicolumn{2}{|c|}{ No information } \\
\hline Below 35 years & 103 & 13 & & \\
\hline 35 to 44 years & 258 & 33 & & \\
\hline 45 to 54 years & 327 & 41 & & \\
\hline 55 and over & 100 & 13 & & \\
\hline \multicolumn{5}{|c|}{ Profession $(n=799)$} \\
\hline Physician & 135 & 17 & 463 & 20 \\
\hline Nurse & 552 & 69 & 1,477 & 66 \\
\hline Other & 112 & 14 & 312 & 14 \\
\hline \multicolumn{5}{|c|}{ Healthcare level $(n=799)$} \\
\hline Primary care & 437 & 55 & 1,105 & 49 \\
\hline Secondary care & 362 & 45 & 1,147 & 51 \\
\hline \multicolumn{5}{|c|}{ Hospital district $(n=802)$} \\
\hline $\mathrm{KL} \mathrm{a}^{\mathrm{a}}$ & 423 & 53 & 1,248 & 55 \\
\hline NSb & 326 & 40 & 888 & 40 \\
\hline $\mathrm{CF}^{\mathrm{c}}$ & 53 & 7 & 116 & 5 \\
\hline
\end{tabular}

aKL $=$ Kymenlaakso hospital district.

bNS $=$ Northern-Savo hospital district.

${ }^{c} \mathrm{CF}=$ Central-Finland hospital district.

\section{Discussion}

\section{Main results}

The results of this study indicate that the TPB variables-the attitude toward the behaviour, the subjective norm, and the perceived behaviour control--are important factors associated with the healthcare professionals' intention to use clinical practice guidelines generally in their decisions on patient care. Consequently, the results confirm suggestions that the TPB is a suitable theoretical basis for implementation of clinical guidelines in multiple healthcare professions' practices $[13,20,46]$.

An important finding for clinical guideline developers and implementers is that both the nurses and the physicians had stronger intention to use clinical guidelines in patient care than other professionals did when other factors in the model were fixed. In particular, this effect was strong among secondary care workers. On the other hand, nurses and physicians had similar intention to utilise clinical guidelines when compared only against each other in a regression model. Thus, our results indicate that contextual factors, such as multiple profession groups or healthcare setting, were important in our model.

In the profession-based models, the factor associated most strongly with intention was the perceived behaviour control for the physicians, but the subjective norm for the nurses and other professionals. These results indicate that, in particular, context- and guideline-based factors either encourage or hinder the intention to use clinical practice guidelines among physicians, and that normative beliefs related to social pressures have a corresponding effect for nurses and other professionals. It can be argued that for successful implementation of clinical guidelines the implementers should recognise and make better use of those context and guideline factors that can have a positive effect on implementation by physicians as well as those normative belief factors with positive effects, such as a superior's support for use of clinical guidelines, for nurses and other professionals [47]. According to the behaviour science perspective $[15,16,38]$, it is necessary 
Table 2: Description of the variables in the models--means (standard deviations)

\begin{tabular}{|c|c|c|c|c|}
\hline Variable & $\begin{array}{l}\text { Overall model } \\
(n=638)\end{array}$ & $\begin{array}{l}\text { Physicians model } \\
(n=123)\end{array}$ & $\begin{array}{l}\text { Nurses model } \\
(n=436)\end{array}$ & $\begin{array}{l}\text { Others model } \\
(n=79)\end{array}$ \\
\hline \multicolumn{5}{|l|}{ Theory of planned behaviour variables } \\
\hline Intention (1 item), scale: $1-7$ a & $5.3(1.3)$ & $5.5(1.2)$ & $5.3(1.3)$ & $5.0(1.3)$ \\
\hline Attitude ( 3 items), scale: $1-7^{a}$ & $5.4(1.2)$ & $5.2(1.3)$ & $5.4(1.2)$ & $5.4(1.2)$ \\
\hline Subjective norm ( 3 items), scale: $1-7^{a}$ & $5.4(1.0)$ & $5.4(1.0)$ & $5.4(1.1)$ & $5.4(1.0)$ \\
\hline Perceived behaviour control (6 items), scale: 1-7a & $4.4(0.8)$ & $4.5(0.8)$ & $4.3(0.9)$ & $4.4(0.8)$ \\
\hline \multicolumn{5}{|l|}{ Individual-level variables for the respondents } \\
\hline Gender $($ male $=0$, female $=1)$ & $0.9(0.3)$ & $0.6(0.5)$ & $0.9(0.2)$ & $0.9(0.2)$ \\
\hline Age & $44.4(8.4)$ & $45.8(8.9)$ & $43.9(8.3)$ & $45.2(7.7)$ \\
\hline Nurse_d (nurse $=1$, physician or other professional $=0$ ) & $0.7(0.5)$ & - & - & - \\
\hline Physician_d (physician $=1$, nurse or other professional $=0$ ) & $0.2(0.4)$ & - & - & - \\
\hline \multicolumn{5}{|l|}{ Organisation-level variables for the respondents } \\
\hline Primary care (primary care $=1$, secondary care $=0$ ) & $0.6(0.5)$ & $0.5(0.5)$ & $0.6(0.5)$ & $0.7(0.5)$ \\
\hline $\mathrm{KL}(\mathrm{KL}=1 \text {, others }=0)^{\mathrm{b}}$ & $0.5(0.5)$ & $0.4(0.5)$ & $0.5(0.5)$ & $0.5(0.5)$ \\
\hline NS $(N S=1 \text {, others }=0)^{b}$ & $0.4(0.5)$ & $0.5(0.5)$ & $0.4(0.5)$ & $0.4(0.5)$ \\
\hline
\end{tabular}

at the first stage in planning of an implementation to identify the beliefs behind the target behaviour where one wishes to see change.

Similar findings to those for the physician group have been reported earlier $[23,39,48,49]$. However, also opposite results have been reported; for example, Puffer and Rashidian [40] found that among nurses the attitude toward the behaviour and the perceived behaviour control are the most important indicators of intention to offer smoking cessation advice. Limbert and Lamb [50] found the subjective norm the strongest indicator of intention to use the asthma guidelines and the attitude toward the behaviour the strongest indicator of intention to use the antibiotic guidelines among physicians. However, these differences from our results could be simply explained by the different target behaviour. This study considered not specific guideline-based behaviours but, instead, professional's general self-reported behaviour in the patient-specific use of guidelines.

The variables of individual and organisation characteristics had no effect or only a modest one on the professionals' intention to use clinical practice guidelines in the profession-based models. The negative effect of the primary care variable in the physicians group may be clinically relevant, highlighting the nature of the work environment for guideline implementers. This phenomenon is described thoroughly by McKenna et al. [51], who analysed studies of barriers to evidence-based practice in primary care. The conclusions were that potential barriers to target behaviour have to be identified specifically in relation to the work environment in which they arise, and that there was only limited high-quality evidence available of this phenomenon.

We found that the intention to use clinical practice guidelines in decision making regarding patient care was, for the most part, positive for all professions. Almost onehalf of the respondents had positive intentions, and only $5 \%$ were negative. This is a positive message for implementation of the EBMeDS in clinical practice. It also confirms our earlier findings among Finnish physicians [52]. It seems that there exist in Finland potential pilot users for automatic reminders based on the clinical guidelines. However, it is equally important to notice that $40 \%$ of physicians and $50 \%$ of nurses and other professionals responded with a 3,4 , or 5 on the seven-point scale here. It seems that the main conclusion is that almost one-half of the respondents were uncertain of their intentions or that intentions may change in changing clinical situations. Another possibility is that the intention item 'I intend to use clinical practice guidelines for my area of 
Table 3: Effects of TPB variables and individual and organisation characteristics on professionals' intention to use clinical guidelines--ordinary least squares models

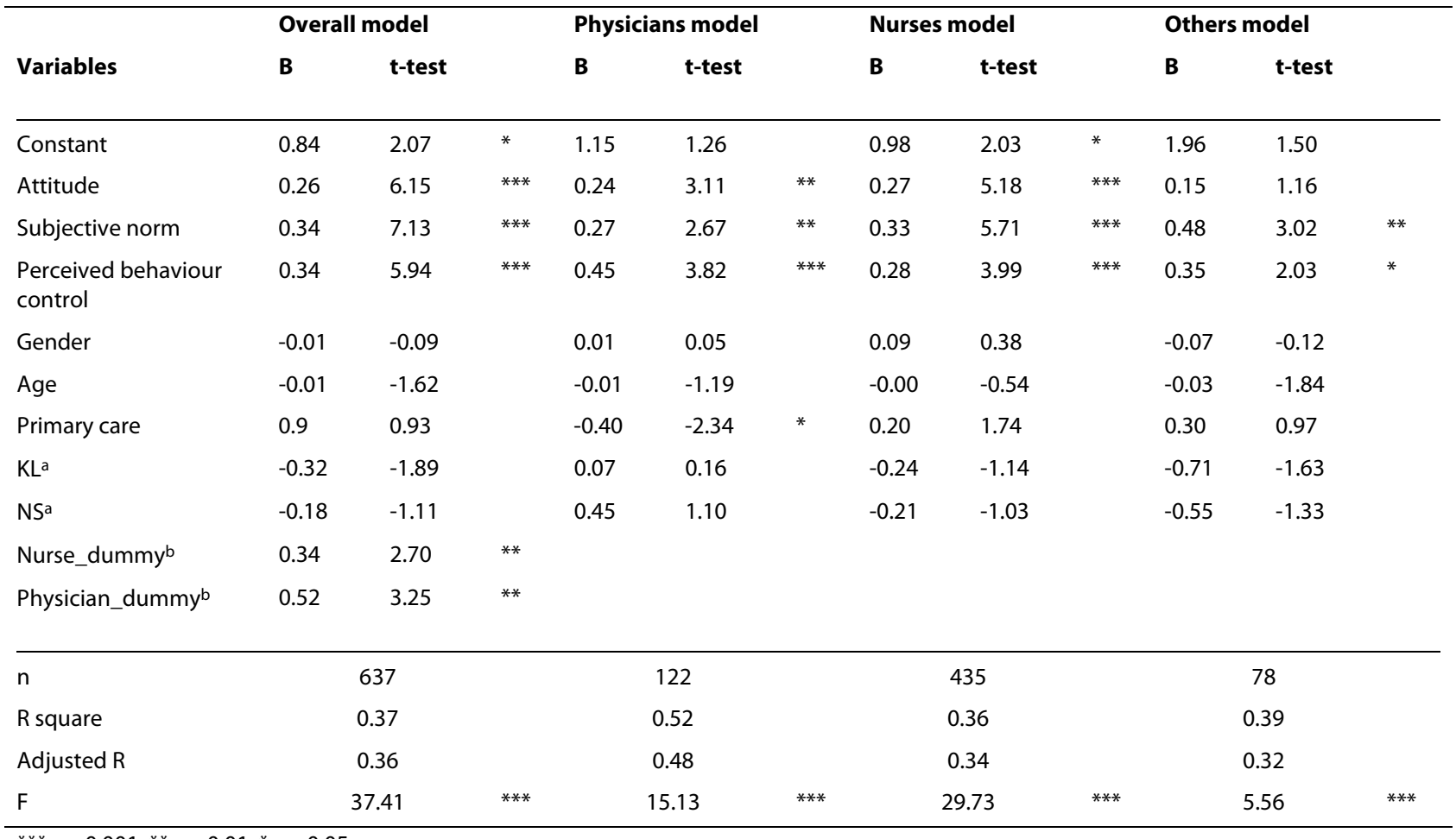

${ }^{* * *} \mathrm{p}<0.001,{ }^{* *} \mathrm{p}<0.01,{ }^{*} \mathrm{p}<0.05$

a Kymenlaakso (KL) and Northern-Savo (NS) hospital districts: dummy variables, with the Central-Finland hospital district (CF) as a reference group.

bThe other profession group was a reference group in the overall model.

specialisation in the decisions I make on the care of patients in the next three months' was too general, and therefore it was hard for professionals to respond more precisely. This, in turn, may simply translate into tailoring behaviour individually according to the patients' needs. These findings are in line with previous evidence on the use of guidelines in Finnish primary care $[53,54]$ and secondary care [7]. For example, the guidelines concerning resuscitation are reported to be used in only $42 \%$ of Finnish health centres [5].

Differences were found in the variance analysis between professions in their intentions to use clinical guidelines. The score for this intention was higher among physicians than among nurses or other professionals. Similar results were reported in the study of Goossens's et al. [55], wherein physicians' and nurses' willingness to adopt a set of guidelines at an academic medical centre were compared. This is an important message for overcoming possible barriers in implementation of the EBMeDS in a multi-profession context. An Australian study [56] also found that education of professionals and motivation of multidisciplinary groups to redesign care processes can aid in overcoming potential barriers to implementation. In addition, our results reaffirm that needs of nurses and other professionals have to be carefully targeted in the development of automatic reminders for those specific groups [57].

\section{Strengths and limitations}

The strength of the study lies in its comprehensiveness: in contrast to previous studies [19] here all major healthcare professions, in both primary and secondary care, were represented. Also, the study concentrated on factors that possibly can affect professionals' intention to use clinical guidelines in their decision making. The choice of factors was based on the TPB and on previous findings $[13,15,17,20,23,40]$. A recent systematic meta-review of factors influencing implementation of clinical guidelines for healthcare professionals listed factors such as characteristics of the guidelines, professionals, patients, and environment that influence use of guidelines [58]. Another review highlighted that evidence concerning proxy measures of clinicians' behaviour is still limited [59].

The study design was a cross-sectional survey at the EBMeDS pilot sites. These results are utilised in system 
development and testing. In comparison of the respondents to the target population (Table 1), it seems that the participants are representative in their gender, profession, and hospital district. In spite of this, only a small difference $(6 \%)$ was found between healthcare levels. This could be a potential source of bias in the interpretation of the study results.

A clear limitation is the low response rate and the missing values for some of the respondents. These may cause non-response bias and, accordingly, problems in interpretation of the results [45]. Since an internet-based webropol format was used, the response rate can be assessed by using the work of Bosnjak et al. [60]: of a total of 2,252 potential respondents, $47 \%$ did not open the questionnaire, $14 \%$ viewed the questionnaire (i.e., opened the web link in their e-mail letter) but did not start to respond, $5 \%$ began to respond but did not complete the questionnaire, and 36\% responded. At least two reasons can be posited to explain the low response rate. First, the busy healthcare workers may have felt that they did not have enough time to complete the survey and the covering letter did not convince them of the need to do so. Second, the internet-based survey and questions may have been too technically difficult or unusual for some. Recent evidence on surveys of healthcare professionals supports these assumptions [61,62].

By profession, $9 \%$ of the physicians' responses had missing values and were therefore excluded from the analyses; the corresponding figure was $21 \%$ for nurses and $29 \%$ for other professionals. Accordingly, the real response rates in the regression models were $26 \%$ for physicians, $29 \%$ for nurses, and $25 \%$ for other professionals. Although the variance explaining the intention ( $\mathrm{R}$ square), at above $28 \%$, can be classed as good [25], the interpretations of the other professionals' regression model (adjusted $\mathrm{R}$ square 0.32 , F value 5.56 ) cannot be practically generalised, because the results came from a low total number of respondents $(n=79)$, who, in addition, represented many, different professions. However, the applicability of the results in the physicians' and nurses' groups is rather good--the variables of the physicians' model explained $48 \%$ (adjusted R square 0.48 , F value 15.13 ) of the variation in the intention to use clinical guidelines, and the 436 nurses were representative clinical guideline users of all relevant nursing professions.

Our main target in the formulation of the questionnaire was the unique EBMeDS study context concerned, not more general approaches $[33,45]$. However, a theorybased approach was used in this formulation [36], and the questionnaire was piloted and refined on the basis of the findings from the pilot tests [33]. These actions confirmed the content validity of the questionnaire. Similarly, the internal consistency of the sum variables was analysed as being adequate (Cronbach's alpha coefficient over
0.8 for each variable). We only used one item related to the intention variable, which can be considered a methodological limitation [17,36] (see Additional File 1). In subsequent analyses, from the same study context, in different survey data $(\mathrm{n}=38$ primary care professionals' responses), we tested the extent of the correlation between a single intention variable ('I intend to do...') and a generalised intention variable ('I except/want/intend to do...') [36]. We found that the single intention variable explained 82\% (adjusted R square 0.82, $\mathrm{F}=164.36, \mathrm{p}<$ 0.001 ) of the variation of the generalised intention variable. Thus, we acknowledge a methodological limitation of our questionnaire formulation, but this potential source of bias seems minor. Finally, it has to be recognised that the results of this study are based on the professionals' self-reported assessments, which were not verified with observations of actual use of clinical guidelines $[23,26]$.

\section{Summary}

Regardless of some limitations of our study, we conclude that we found some support for the idea of using TPB for implementation of clinical practice guidelines in multiple professional groups. The new finding that is of importance for guideline developers and implementers is that, when compared to other professionals, both nurses and physicians had positive intention to use clinical practice guidelines in patient care. This reaffirms the general contention that different strategies need to be in place in targeting of different professional groups. It could be worth investigating whether involving the various groups more intensively from the beginning of guideline development all the way through to implementation, or supporting guideline uptake, would have a positive effect on adoption in their decision making.

\section{Additional material}

Additional file 1 The guidelines and background questions PDF.

\section{Competing interests}

The authors declare that they have no competing interests.

\section{Authors' contributions}

All authors conceived the study and designed the questionnaire. TK, MK, and PR were responsible for data collection. TK analysed the data, and PR supervised the analyses. TK led the writing process, and all authors commented on sequential drafts and approved the final version of the manuscript.

\section{Acknowledgements}

This study was funded by the Finnish Funding Agency for Technology and Innovation, the National Institute for Health and Welfare, Duodecim Medical Publications Ltd, and ProWellness Ltd. We are grateful to the participants at the EBMeDS pilot sites who gave their time to participate in the data collection. We are grateful also to Adjunct Professor Anna-Mari Aalto from the National Institute for Health and Welfare, who participated in designing the questionnaire; to assistants Tiina Tala, Saara Ojala, and Heidi Korhonen from the EBMeDS study group for data collection and coding; to other members from the EBMeDS 
study group and to statistical analysts Mika Helminen and Jani Raitanen from the Tampere School of Public Health for their help.

\section{Author Details}

'Tampere School of Public Health, University of Tampere, Medisiinarinkatu 3, Tampere, Finland, ${ }^{2}$ City of Tampere, Social and Primary Care Services/Children and Youth Health Services, Tampere, Finland, ${ }^{3}$ National Institute for Health and Welfare, Mannerheimintie 166, Helsinki, Finland, ${ }^{4}$ The Finnish Medical Society Duodecim, Kalevankatu 11A, Helsinki, Finland and ${ }^{5}$ The Ministry of Social Affairs and Health, Meritullinkatu 8, Helsinki, Finland

Received: 5 October 2009 Accepted: 29 June 2010

Published: 29 June 2010

\section{References}

1. Davis DA, Taylor-Vaisey A: Translating guidelines into practice. A systematic review of theoretic concepts, practical experience and research evidence in the adoption of clinical practice guidelines. CMAJ 1997, 157(4):408-416.

2. Varonen H, Jousimaa J, Helin-Salmivaara A, Kunnamo I: Electronic primary care guidelines with links to Cochrane reviews--EBM Guidelines. Fam Pract 2005, 22(4):465-469.

3. Hamalainen P, Reponen J, Winblad I: eHealth of Finland. Check point 2006. Helsinki: Stakes, Report 1; 2007:1-55.

4. Kuronen R, Jallinoja P, Ilvesmaki V, Patja K: IImplementing current care clinical guidelines associated with cardiovascular diseases]. Suomen Laakarilehti 2006, 61(44):4571-4577.

5. Makinen M, Castren M, Nurmi J, Pappinen J, Niemi-Murola L: [Factors associated with uptake of the resuscitation guideline: a primary healthcare survey]. Finnanest 2005, 38(5):481.

6. Miilunpalo S, Toropainen E, Moisio P: Implementation of guidelines in primary healthcare. A challenge for the municipal health centres in Finland. Scand J Prim HealthCare 2001, 19(4):227-231.

7. Roine RP, Kaila M, Nuutinen M, Mantyranta T, Nuutinen L, Auvinen O, Mustajoki P: The execution of current treatment praxis recommendations in the specialized healthcare. Duodecim 2003, 119(5):399-406.

8. Cabana MD, Rand CS, Powe NR, Wu AW, Wilson MH, Abboud PA, Rubin HR: Why don't physicians follow clinical practice guidelines? A framework for improvement. JAMA 1999, 282(15):1458-1465.

9. Grimshaw JM, Eccles MP: Is evidence-based implementation of evidence-based care possible? Med J Aust 2004, 180(6 Suppl):S50-51.

10. Grimshaw JM, Thomas RE, MacLennan G, Fraser C, Ramsay CR, Vale L, Whitty P, Eccles MP, Matowe L, Shirran L, et al:: Effectiveness and efficiency of guideline dissemination and implementation strategies. Health Technol Assess 2004, 8(6):iii-iv. 1-72

11. Grol R, Grimshaw J: From best evidence to best practice: effective implementation of change in patients' care. Lancet 2003, 362(9391):1225-1230

12. Moulding NT, Silagy CA, Weller DP: A framework for effective management of change in clinical practice: dissemination and implementation of clinical practice guidelines. Qual HealthCare 1999, 8(3):177-183.

13. Grimshaw JM, Eccles MP, Walker AE, Thomas RE: Changing physicians' behavior: what works and thoughts on getting more things to work. $J$ Contin Educ Health Prof 2002, 22(4):237-243.

14. Grol RP, Bosch MC, Hulscher ME, Eccles MP, Wensing M: Planning and studying improvement in patient care: the use of theoretical perspectives. Milbank Q 2007, 85(1):93-138.

15. Ajzen I: The theory of planned behaviour. Organ Behav Hum Decis Process 1991, 50:179-211.

16. Armitage $\mathrm{CJ}$, Conner M: Efficacy of the theory of planned behaviour: a meta-analytic review. Br J Soc Psychol 2001, 40(Pt 4):471-499.

17. Constructing a TpB questionnaire: conceptual and methodological considerations [http://people.umass.edu/aizen/pdf/ tpb.measurement.pdf

18. Perkins MB, Jensen PS, Jaccard J, Gollwitzer P, Oettingen G, Pappadopulos E, Hoagwood KE: Applying theory-driven approaches to understanding and modifying clinicians' behavior: what do we know? Psychiatr Serv 2007, 58(3):342-348
19. Godin G, Belanger-Gravel A, Eccles M, Grimshaw J: Healthcare professionals' intentions and behaviours: a systematic review of studies based on social cognitive theories. Implement Sci 2008, 3:36

20. Eccles M, Grimshaw J, Walker A, Johnston M, Pitts N: Changing the behavior of healthcare professionals: the use of theory in promoting the uptake of research findings. J Clin Epidemiol 2005, 58(2):107-112.

21. Foy R, Walker A, Ramsay C, Penney G, Grimshaw J, Francis J: Theory-based identification of barriers to quality improvement: induced abortion care. Int J Qual HealthCare 2005, 17(2):147-155.

22. Pessoa-Silva CL, Posfay-Barbe K, Pfister R, Touveneau S, Perneger TV, Pittet $D$ : Attitudes and perceptions toward hand hygiene among healthcare workers caring for critically ill neonates. Infect Control Hosp Epidemiol 2005, 26(3):305-311.

23. Maue SK, Segal R, Kimberlin CL, Lipowski EE: Predicting physician guideline compliance: an assessment of motivators and perceived barriers. Am J Manag Care 2004, 10(6):383-391.

24. Eccles MP, Hrisos S, Francis J, Kaner EF, Dickinson HO, Beyer F, Johnston M: Do self-reported intentions predict clinicians' behaviour: a systematic review. Implement Sci 2006, 1:28.

25. Sheeran $\mathrm{P}$ : Intention-behavior relations: a conceptual and empirical review. EurRev Soc Psychol 2002, 12:1-36.

26. Harrison S, Dowswell G, Wright J: Practice nurses and clinical guidelines in a changing primary care context: an empirical study. J Adv Nurs 2002, 39(3):299-307.

27. Mazza D, Russell SJ: Are GPs using clinical practice guidelines? Aust Fam Physician 2001, 30(8):817-821.

28. Langley C, Faulkner A, Watkins C, Gray S, Harvey I: Use of guidelines in primary care-practitioners' perspectives. Fam Pract 1998, 15(2):105-111.

29. Carlsen B, Norheim OF: 'What lies beneath it all?' - an interview study of GPs' attitudes to the use of guidelines. BMC Health Serv Res 2008, 8:218.

30. EBMeDS context-sensitive guidance at the point of care [http:// www.ebmeds.org/ebmeds/ebmeds home.asp]

31. Developing an evidence based medicine decision support system integrated with EPRs utilizing standard data elements [http:// www.cs.vu.nl/ annette/FinalVersions/Komulainen.pdf

32. Varonen H, Kaila M, Kunnamo I, Komulainen J, Mantyranta T: Computerised decision support: the way towards advisory patient record. Duodecim 2006, 122(10):1174-1181.

33. McColl E, Jacoby A, Thomas L, Soutter J, Bamford C, Steen N, Thomas R, Harvey E, Garratt A, Bond J: Design and use of questionnaires: a review of best practice applicable to surveys of health service staff and patients. Health Technol Assess 2001, 5(31):1-256.

34. Elovainio M, Eccles M, Makela M: Attitudes towards guidelines and a scale for measuring them. In Changing Professional Practice: Theory and practice of clinical guidelines implementation Edited by: Thorsen T, Makela M. Copenhagen: DSI Danish Institute for Health Services Research and Development = DSI Institut for Sundhedsvaesen; 1999:153-167.

35. Job Content Questionnaire (JCQ) Instruction Manual and Sample Responses [http://www.cawlocal555.ca/jjesc/jjescmanual0504.pdf

36. Constructing questionnaires based on the theory of planned behaviour. A manual for health services researchers [http://wwwunix.oit.umass.edu/ aizen/pdf/ Francis\%20etal.TPB\%20research\%20manual.pdf]

37. Ajzen I: The principle of compatibility. In Attitudes, Personality and behavior Illinois: The Dorsey Press; 1988:92-111.

38. Fishbein M, Ajzen I: Belief, attitude, intention and behaviour. Massachusetts: Addison-Wesley Publishing Company; 1975:288-334

39. Walker AE, Grimshaw JM, Armstrong EM: Salient beliefs and intentions to prescribe antibiotics for patients with a sore throat. Br J Health Psychol 2001, 6(Part 4):347-360

40. Puffer $S$, Rashidian A: Practice nurses' intentions to use clinical guidelines. J Adv Nurs 2004, 47(5):500-509.

41. Mantyranta T, Kaila M, Varonen H, Makela M, Roine R, Lappalainen J: Implementation of guidelines. The Finnish Medical Society Duodecim 2003.

42. Tabachnick BG, Fidell LS: Principal components and factor analysis. In Using Multivariate Statistics 4th edition. Boston: Allyn and Bacon; 2001:582-652.

43. Bland JM, Altman DG: Cronbach's alpha. BMJ 1997, 314(7080):572.

44. Toothaker LE: Multiple comparisons procedures Thousand Oaks CA: Sage Publications: 1993. 
45. Campbell MJ, Machin D: Medical Statistics: a commonsense approach 3rd edition. Chichester: John Wiley \& Sons Ltd; 2002.

46. Michie S, Johnston M, Abraham C, Lawton R, Parker D, Walker A: Making psychological theory useful for implementing evidence based practice: a consensus approach. Qual Saf HealthCare 2005, 14(1):26-33

47. Leeman J, Baernholdt M, Sandelowski M: Developing a theory-based taxonomy of methods for implementing change in practice. J Adv Nurs 2007, 58(2):191-200.

48. Bonetti D, Pitts NB, Eccles M, Grimshaw J, Johnston M, Steen N, Glidewel L, Thomas R, Maclennan G, Clarkson JE, et al:: Applying psychological theory to evidence-based clinical practice: identifying factors predictive of taking intra-oral radiographs. Soc Sci Med 2006, 63(7):1889-1899.

49. Millstein SG: Utility of the theories of reasoned action and planned behavior for predicting physician behavior: a prospective analysis. Health Psychol 1996, 15(5):398-402.

50. Limbert C, Lamb R: Doctors' use of clinical guidelines: two applications of the Theory of Planned Behaviour. Psychology, Health \& Medicine 2002, 7(3):301-310.

51. McKenna $\mathrm{H}$, Ashton S, Keeney S: Barriers to evidence based practice in primary care: a review of the literature. Int J Nurs Stud 2004, 41(4):369-378.

52. Varonen $\mathrm{H}$, Kortteisto $\mathrm{T}$, Kaila M: What may help or hinder the implementation of computerized decision support systems (CDSSs): a focus group study with physicians. Fam Pract 2008, 25(3):162-167.

53. Kaila M, Rintanen H, Saalasti-Koskinen U: [Uptake of Current Care guidelines in primary healthcare]. Suomen Laakarilehti 2006 , 61(19):2142-2143.

54. Lehtomaki L: [From national guidelines to house rules of health centre]. In Ph.D. Thesis University of Tampere; 2009.

55. Goossens A, Bossuyt PM, de Haan RJ: Physicians and nurses focus on different aspects of guidelines when deciding whether to adopt them: an application of conjoint analysis. Med Decis Making 2008, 28(1):138-145.

56. Scott IA, Denaro CP, Bennett CJ, Mudge AM: Towards more effective use of decision support in clinical practice: what the guidelines for guidelines don't tell you. Intern Med J 2004, 34(8):492-500.

57. Randell R, Mitchell N, Thompson C, McCaughan D, Dowding D: Supporting nurse decision making in primary care: exploring use of and attitude to decision tools. Health Informatics J 2009, 15(1):5-16.

58. Francke AL, Smit MC, de Veer AJ, Mistiaen P: Factors influencing the implementation of clinical guidelines for healthcare professionals: a systematic meta-review. BMC Med Inform Decis Mak 2008, 8:38.

59. Hrisos S, Eccles MP, Francis JJ, Dickinson HO, Kaner EF, Beyer F, Johnston M: Are there valid proxy measures of clinical behaviour? a systematic review. Implement Sci 2009, 4:37.

60. Bosnjak M, Tuten TL: Classifying response behaviors in web-based surveys. Journal of Computer-Mediated Communication 2001, 6(3):

61. Lusk C, Delclos GL, Burau K, Drawhorn DD, Aday LA: Mail versus internet surveys: determinants of method of response preferences among health professionals. Eval Health Prof 2007, 30(2):186-201.

62. VanGeest JB, Johnson TP, Welch VL: Methodologies for improving response rates in surveys of physicians: a systematic review. Eval Health Prof 2007, 30(4):303-321

63. Eccles MP, Hrisos S, Francis JJ, Steen N, Bosch M, Johnston M: Can the collective intentions of individual professionals within healthcare teams predict the team's performance: developing methods and theory. Implement Sci 2009, 4:24.

doi: 10.1186/1748-5908-5-51

Cite this article as: Kortteisto et al., Healthcare professionals' intentions to use clinical guidelines: a survey using the theory of planned behaviour Implementation Science 2010, 5:51

\section{Submit your next manuscript to BioMed Central} and take full advantage of:

- Convenient online submission

- Thorough peer review

- No space constraints or color figure charges

- Immediate publication on acceptance

- Inclusion in PubMed, CAS, Scopus and Google Scholar

- Research which is freely available for redistribution

Submit your manuscript at www.biomedcentral.com/submit
C BioMed Central 